\title{
ABC transporters P-gp and Bcrp do not limit the brain uptake of the novel antipsychotic and anticonvulsant drug cannabidiol in mice.
}

Natalia Brzozowska, Kong M Li, Xiao Suo Wang, Jessica Booth, Jordyn Stuart, Iain S McGregor, Jonathon C Arnold

Cannabidiol (CBD) is currently being investigated as a novel therapeutic for the treatment of CNS disorders like schizophrenia and epilepsy. ABC transporters such as P-glycoprotein (P-gp) and breast cancer resistance protein (Bcrp) mediate pharmacoresistance in these disorders. P-gp and Bcrp are expressed at the blood brain barrier (BBB) and reduce the brain uptake of substrate drugs including various current antipsychotics and anticonvulsants. It is therefore important to assess whether CBD may be prone to treatment resistance mediated by P-gp and Bcrp. Moreover, it has become common practice in the drug development of CNS agents to screen against ABC transporters to help isolate lead compounds with optimal pharmacokinetic properties. The current study aimed to assess whether P-gp and Bcrp impacts the brain transport of CBD by comparing CBD tissue concentrations in wild-type (WT) mice versus mice devoid of $A B C$ transporter genes.

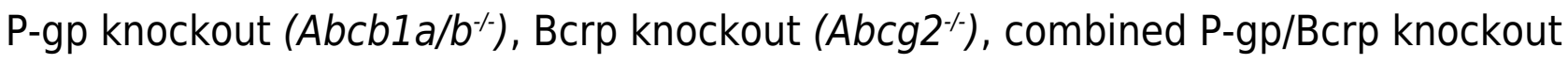

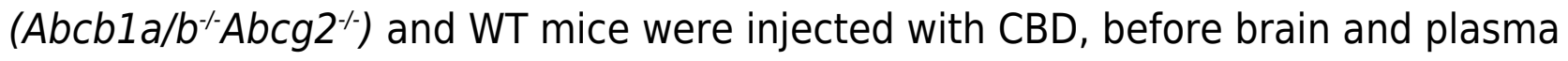
samples were collected and determined at various time-points. CBD results were compared with the positive control risperidone and 9-hydroxy risperidone, antipsychotic drugs that are established $A B C$ transporter substrates. Brain and plasma concentrations of CBD were not greater in P-gp, Bcrp or P-gp/Bcrp knockout mice than WT mice. In comparison, the brain/plasma concentration ratios of risperidone and 9-hydroxy risperidone were profoundly higher in P-gp knockout mice than WT mice. These results suggest that CBD is not a substrate of P-gp or Bcrp and may be free from the complication of reduced brain uptake by these transporters. Such findings provide favorable evidence for the therapeutic development of CBD in the treatment of various CNS disorders. 


\section{ABC transporters P-gp and Bcrp do not limit the brain uptake of the novel antipsychotic and anticonvulsant drug cannabidiol in mice.}

Natalia I. Brzozowska ${ }^{1,2}$, Kong M. Li ${ }^{2}$, Xiao-Suo Wang ${ }^{3}$, Jessica Booth ${ }^{4}$, Jordyn Stuart ${ }^{1,4}$, Iain S. McGregor $^{1,4}$ and Jonathon C. Arnold ${ }^{1,2}$

$8{ }^{1}$ The Lambert Initiative of Cannabinoid Therapeutics, The Brain and Mind Centre, University of

9 Sydney, Camperdown, NSW, Australia

102 Discipline of Pharmacology, School of Medical Science, University of Sydney, Camperdown,

11 NSW, Australia

$12{ }^{3}$ Bosch Mass Spectrometry Facility, Bosch Institute, Sydney Medical School, The University of

13 Sydney, Camperdown, NSW, Australia

$14{ }^{4}$ Psychopharmacology Laboratory, School of Psychology, Faculty of Science, University of

\section{Correspondence}

A/Prof Jonathon Arnold

Brain \& Mind Centre Room No 503, Building G | 94 Mallet Street, Sydney, NSW, 2050, Australia

Email: jonathon.arnold@sydney.edu.au 


\section{Abbreviations}

$33 \mathrm{CBD}$, cannabidiol; $\mathrm{THC}, \Delta^{9}$-tetrahydrocannabinol; $\mathrm{ABC}$ transporters, adenosine triphosphate

34 (ATP) binding cassette transporters; P-gp, P-glycoprotein; Bcrp, breast cancer resistance protein;

35 WT, wild-type; 9-OH risperidone, 9-hydroxy risperidone; BBB, blood brain barrier; FVB, friend

36 virus B-type mice; s.c, subcutaneous; EDTA, ethylenediaminetetraacetic acid; LC-MS/MS,

37 liquid chromatography and tandem mass spectrometry (triple quadrupole mass spectrometer);

38 QC, quality control; SPE, solid phase extraction; LOQ, limits of quantification; $\mathrm{CB}_{1}$, cannabinoid

391 receptor.

40

41

42

43

44

45

46 


\section{Abstract}

47 Cannabidiol (CBD) is currently being investigated as a novel therapeutic for the treatment of

48 CNS disorders like schizophrenia and epilepsy. ABC transporters such as P-glycoprotein (P-gp)

49 and breast cancer resistance protein (Bcrp) mediate pharmacoresistance in these disorders. P-gp and Bcrp are expressed at the blood brain barrier $(\mathrm{BBB})$ and reduce the brain uptake of substrate

51 drugs including various current antipsychotics and anticonvulsants. It is therefore important to assess whether $\mathrm{CBD}$ may be prone to treatment resistance mediated by P-gp and Bcrp. Moreover, it has become common practice in the drug development of CNS agents to screen against $\mathrm{ABC}$ transporters to help isolate lead compounds with optimal pharmacokinetic properties. The current study aimed to assess whether P-gp and Bcrp impacts the brain transport of CBD by comparing CBD tissue concentrations in wild-type (WT) mice versus mice devoid of ABC transporter genes. P-gp knockout $\left(A b c b l a / b^{-/}\right)$, Bcrp knockout (Abcg2 $\left.2^{--}\right)$, combined Pgp/Bcrp knockout $\left(A b c b l a / b^{-/} A b c g 2^{-/-}\right)$and WT mice were injected with $\mathrm{CBD}$, before brain and plasma samples were collected and determined at various time-points. CBD results were compared with the positive control risperidone and 9-hydroxy risperidone, antipsychotic drugs that are established $\mathrm{ABC}$ transporter substrates. Brain and plasma concentrations of $\mathrm{CBD}$ were not greater in P-gp, Bcrp or P-gp/Bcrp knockout mice than WT mice. In comparison, the brain/plasma concentrations of risperidone and 9-hydroxy risperidone were profoundly higher in P-gp knockout mice than WT mice. These results suggest that CBD is not a substrate of P-gp or

65 Bcrp and may be free from the complication of reduced brain uptake by these transporters. Such

66 findings provide favorable evidence for the therapeutic development of CBD in the treatment of 67 various CNS disorders. 


\section{Introduction}

68 Cannabidiol (CBD), a non-psychoactive constituent of cannabis, displays much potential as a novel therapeutic treatment for various CNS disorders including schizophrenia and epilepsy (Bumb, Enning \& Leweke, 2015; Iseger \& Bossong, 2015; Longo, Friedman \& Devinsky, 2015). CBD has anticonvulsant effects in animal models of epilepsy and schizophrenia (Arnold, Boucher \& Karl, 2012; Jones et al., 2012; Jones et al., 2010; Mao et al., 2015). Anecdotal reports and early clinical findings support CBD's ability to reduce seizure rates in humans with a good safety profile (Rosenberg et al., 2015). Phase 3 clinical trails are currently investigating CBD in the treatment of epilepsy, most notably in severe and pharmacoresistant childhood epilepsies. There is also promising evidence that CBD is a novel antipsychotic, with a phase 2 clinical trial showing CBD reduced symptoms in schizophrenia patients with comparable efficacy to a conventional antipsychotic drug without producing extrapyramidal side-effects, sedation or weight gain (Bumb, Enning \& Leweke, 2015; Iseger \& Bossong, 2015; Leweke et al., 2012). Numerous further clinical trials are currently underway examining the efficacy of CBD in treating schizophrenia. The precise pharmacodynamic mechanisms responsible for CBD's

82 anticonvulsant and antipsychotic efficacy are hotly debated and may involve inhibition of degradation of the endocannabinoid anandamide. Although there are numerous other contenders as $\mathrm{CBD}$ is a promiscuous drug that interacts with multiple drug targets including G-proteincoupled receptor 55 (GPR55), transient receptor potential vanilloid type 1 (TRPV1) channels, and adenosine transporters (Leweke et al., 2012; McPartland et al., 2015; Rosenberg et al. 2015).

Resistance to treatment is a major stumbling block in the clinical management of epilepsy 
88 and schizophrenia. Approximately $30 \%$ of both schizophrenia and epilepsy patients do not

89 respond adequately to drug therapy (Hoosain et al., 2015; van Os \& Kapur, 2009) and ATP-

90 binding cassette (ABC) transporters play a role in treatment-resistance (Bebawy \& Chetty, 2008;

91 Brandt et al., 2006). ABC transporters are a large superfamily of proteins that actively transport

92 substrates across biological membranes and thus influence the disposition of substrate drugs

93 (Hee Choi \& Yu, 2014; Kathawala et al., 2015). The best characterized ABC transporters are P-

94 glycoprotein (P-gp, $A b c b 1)$ and breast cancer resistance protein (Bcrp, Abcg2), which are both

95 efflux pumps localized at various pharmacological barriers in the body including the blood brain

96 barrier (Löscher \& Potschka, 2005). Many antipsychotic and anticonvulsant drugs are substrates

97 of P-gp, which strongly limits the brain accumulation of these agents by extruding the drugs

98 from the brain parenchyma back into the blood (Boulton et al., 2002; Doran et al., 2005; Luna-

99 Tortós, Fedrowitz \& Löscher, 2008; Zhang et al., 2012). Few studies have examined the

100 substrate profile of CNS drugs for Bcrp, although lamotrigine has recently been demonstrated to

101 be a substrate of human and mouse Bcrp (Römermann, Helmer \& Löscher, 2015).

102 There is evidence that genetic variation in P-gp influences treatment response to

103 antipsychotic and antiepileptic drugs such as olanzapine, risperidone, paliperidone (9-hydroxy

104 risperidone, the active metabolite of risperidone), phenobarbital and phenytoin (French, 2013;

105 Wolking et al., 2015). Furthermore, P-gp and Bcrp are upregulated at the BBB in epilepsy and

106 schizophrenia and contribute to pharmacoresistance by limiting the brain uptake and efficacy of

107 anticonvulsant and antipsychotic drugs (Aronica et al., 2005; Bauer et al., 2014; de Klerk et al., 108 2010; Lazarowski et al., 2007; Van Vliet et al., 2005). Drugs that are not substrates of ABC

109 transporters will then make better therapeutics, as they will be immune to drug resistance

110 mediated by these proteins. Indeed, it has become common practice in drug development to 
111 screen against $\mathrm{ABC}$ transporters to help isolate lead compounds that are less likely to fail in

112 clinical trials due to suboptimal pharmacokinetic properties. It is therefore important to establish

113 whether $\mathrm{CBD}$ is an $\mathrm{ABC}$ transporter substrate. We have shown that the main psychoactive

114 constituent of cannabis, $\Delta^{9}$-tetrahydrocannabinol (THC) is a substrate of both P-gp and Bcrp

115 (Spiro et al., 2012). CBD, an isomer of THC, inhibits both P-gp and Bcrp transport (Feinshtein et

116 al., 2013b; Zhu et al., 2006), although results have not been consistent for P-gp (Holland et al.,

117 2006). Inhibitors are often substrates so there is a need to clarify whether CBD is a substrate of

118 P-gp or Bcrp and whether this has implications for the brain uptake of the compound.

119 The present study assesses whether CBD is a substrate of P-gp and Bcrp by utilising mice

120 devoid of these $\mathrm{ABC}$ transporter genes singly or in combination. If $\mathrm{CBD}$ accumulates at greater

121 concentrations in the brain of $\mathrm{ABC}$ transporter knockout animals than wild-type mice under the

122 same experimental conditions, then this provides evidence that it is an ABC transporter substrate.

123 The results of CBD are compared with a positive control risperidone and 9-hydroxy risperidone,

124 as these antipsychotic drugs are established P-gp substrates (Doran et al., 2005). Our results will

125 be useful in the evaluation of $\mathrm{CBD}$ as a therapeutic agent for CNS disorders from a

126 pharmacokinetic perspective. If P-gp or Bcrp do not limit the brain concentrations of CBD, it

127 implies that $\mathrm{CBD}$ might be free from drug resistance that is mediated by these $\mathrm{ABC}$ transporters.

128

\section{Materials and methods}

\subsection{Animals}

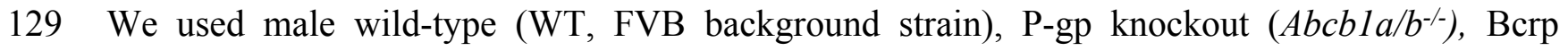

130 knockout $\left(A b c g 2^{-/-}\right)$and combined P-gp/Bcrp knockout ( $\left.A b c b l a / b^{-/} A b c g 2^{-/-}\right)$mice aged between

131 4-5 months weighing between 25-30 g (Taconic farms, New York, USA). P-gp, Bcrp and P- 
132 gp/Bcrp knockout mice were developed by Professor Alfred Schinkel and colleagues at the

133 Netherlands Cancer Institute, Amsterdam (Jonker et al., 2002; Schinkel et al., 1995; Schinkel et

134 al., 1997). Mice were housed in groups of 4-6 mice per cage and kept under a standard $12 \mathrm{~h}$

135 light/dark schedule. Food and water were available ad libitum and all cages contained various

136 forms of environmental enrichment such as a mouse house igloo and running wheel, a paper roll,

137 a climbing ring, tissue paper and sunflower seeds. The University of Sydney's Animal Ethics

138 Committee approved all experimental procedures undertaken (Protocol number: K21/1-

139 2013/3/5924) and all procedures were in accordance with the Australian Code of Practice for the

140 Care and Use of Animals for Scientific Purposes.

141

\subsection{Drug treatment}

142 CBD (THC Pharm, Frankfurt, Germany) was dissolved in a mixture of ethanol, Tween 80, and

143 saline (1:1:18) (Long et al., 2013; Todd \& Arnold, 2016) and administered via subcutaneous (s.c)

144 injection at a dose of $10 \mathrm{mg} / \mathrm{kg}$ (Doran et al., 2005; Pacchioni et al., 2010). Risperidone (Sequioa

145 Pharmaceuticals, United Kingdom) was dissolved in a solution of $0.9 \%$ saline and $1 \%$ acetic acid

146 and injected s.c. at $3 \mathrm{mg} / \mathrm{kg}$. All drugs were freshly prepared before use and made at an injection

147 volume of $10 \mathrm{ml} / \mathrm{kg}$ of body weight. At numerous time-points post-injection of CBD (1, 2 and 3

148 h) and risperidone (1 and 3 h), P-gp knockout, Bcrp knockout, P-gp/Bcrp knockout and WT mice

149 were lightly anesthetised with isoflurane and blood collected via cardiac puncture. Blood

150 samples were stored in ethylenediaminetetraacetic acid (EDTA) coated tubes to avoid

151 coagulation and kept on ice before separation of plasma (Spiro et al., 2012). To separate the

152 plasma from the blood, samples were centrifuged at $3000 \mathrm{rpm}$ for $10 \mathrm{~min}$ at $4^{\circ} \mathrm{C}$ and the plasma

153 collected in clean eppendorf tubes (Wang et al., 2004). The brains were immediately extracted 
154 and snap frozen in liquid nitrogen. Both the brain and plasma samples were stored at $-80^{\circ} \mathrm{C}$

155 before LC-MS/MS analysis.

156

\subsection{Quantification of CBD in brain and blood samples}

157 CBD was extracted using a previously outlined method from our group (Johnston et al., 2014). In

158 brief, a deuterated $\mathrm{CBD}-\mathrm{D}_{3}$ internal standard solution was added to every brain or plasma sample

159 (see Figure 1). Calibration standards and quality control (QC) samples were prepared by spiking

160 drug-free mouse plasma or drug-free brain homogenates, at linear concentrations from 10-400

$161 \mathrm{ng} / \mathrm{g}$ of CBD for brain analysis and 10-300 $\mathrm{ng} / \mathrm{ml}$ of CBD for plasma analysis. The standards

162 were vortexed and treated identically to other samples. Half brains were homogenised in $\mathrm{dH}_{2} \mathrm{O}$ at

163 a 1:6 ratio (w/v) with $1 \mathrm{~mL}$ brain homogenate. For plasma analysis, $0.5 \mathrm{~mL}$ of a sample was

164 used. Brain and plasma samples were prepared by slowly adding $2 \mathrm{~mL}$ ice-cold acetonitrile,

165 mixed thoroughly and centrifuged at $3000 \mathrm{rpm}$ for 10 minutes. The acetonitrile was decanted

166 into clean tubes and all samples were evaporated using the Genevac EZ-2 evaporation system for

167 approximately 3-4 hours. After reconstituting the samples with $2 \mathrm{~mL} \mathrm{dH}_{2} 0$ the samples were

168 loaded onto Styre Screen ${ }^{\circledR}$ SSTHC063 solid-phase extraction (SPE) columns (60 mg/3 ml) from

169 United Chemical Technologies (Horsham, PA, USA). Columns were then washed with $1 \mathrm{~mL}$

170 water/acetonitrile/ $\mathrm{NH}_{4} \mathrm{OH}(84: 15: 1)$ and dried thoroughly under vacuum (10 mm $\mathrm{Hg}$ ) for $10-15$

171 minutes. Samples were eluted from the column by adding $3 \mathrm{~mL}$ of hexane/ethyl acetate/glacial

172 acetic acid (49:49:2). Extracts were completely dried under a nitrogen gas stream at $60^{\circ} \mathrm{C}$ for 5-

17310 minutes and reconstituted with $50 \mu \mathrm{l}$ initial mobile phase $(40 \%$ methanol and $60 \% 10 \mathrm{mM}$

174 ammonium acetate) for analysis. All quantification was performed using a Shimadzu 8030 triple

175 quadrupole mass spectrometer. The mobile phase consisted of (A) $10 \mathrm{mM}$ ammonium acetate in 
176 water and (B) methanol. The limits of quantification (LOQ) for plasma analysis were $1.5 \mathrm{ng} / \mathrm{ml}$

177 and $11.5 \mathrm{ng} / \mathrm{g}$ for brain analysis.

178

\subsection{Quantification of risperidone and 9-hydroxy risperidone in brain and blood samples}

179 For plasma analysis, $10 \mu \mathrm{l}$ of methyl-risperidone $(10 \mu \mathrm{M})$ internal standard (IS) solution and 0.5

$180 \mathrm{~mL}$ of $\mathrm{PO}_{4}$ buffer ( $\mathrm{pH} 5.0$ ) were added to each $0.1 \mathrm{~mL}$ sample of plasma. Calibration standards

181 were prepared by spiking drug-free mouse plasma at concentrations of 2-200 $\mathrm{ng} / \mathrm{ml}$ for

182 risperidone and 9-hydroxy risperidone. The standards were vortexed and treated identically to

183 other plasma samples. For extraction, plasma samples underwent SPE using Varian SPEC 3 mL

184 MP3 (15 mg) microcolumns from Agilent (Santa Clara, CA, USA). Columns were first

185 conditioned by adding $0.5 \mathrm{~mL}$ methanol followed by $0.5 \mathrm{~mL} 0.1 \mathrm{M} \mathrm{PO}$ buffer ( $\mathrm{pH} 5.0)$. Plasma

186 samples were then loaded onto the column. The columns were washed in $0.5 \mathrm{~mL}$ of acetic acid

187 (1 M) and $0.5 \mathrm{~mL}$ methanol and then dried under vacuum for approximately 2 minutes. The 188 samples were eluted from the column using $1 \mathrm{~mL}$ of freshly prepared

189 dichloromethane/isopropanol/ammonia (80:20:2). The elutant was evaporated to dryness using a

190 SpeedVac centrifugal evaporator. Samples were reconstituted with $200 \mu 1$ of $50 \%$ acetonitrile.

191 For brain analysis, brains were dissected in half, weighed and one half of the brain was

192 homogenised in $\mathrm{dH}_{2} \mathrm{O}$ at a 1:2 ratio (w/v). All samples and calibrators received $50 \mu \mathrm{l}$ of $100 \mathrm{nM}$

193 internal standard. Calibrators were made up of $1.5 \mathrm{~mL}$ of $0.1 \mathrm{M}$ phosphate buffer (pH 6) spiked

194 with linear concentrations of 1-100 $\mathrm{nM}$ of risperidone and 9-hydroxy risperidone. Sample

195 homogenates were centrifuged at $14,000 \mathrm{~g}$ for 10 minutes and the supernatant collected. The

196 brain supernatant underwent identical preparation and extraction as plasma samples and the

197 elutant evaporated accordingly. Samples were reconstituted with $50 \mu 1$ of mobile phase A. The 
198 linear gradient solutions consisted of mobile phase (A) $5 \mathrm{mM}$ ammonium formate (pH 6) and (B)

$19990 \%$ acetonitrile. All quantification was performed using triple quadrupole liquid

200 chromatography-mass spectrometry (Agilent 6460). The LOQ for brain analysis was $1.5 \mathrm{ng} / \mathrm{g}$

201 and $1 \mathrm{ng} / \mathrm{ml}$ for plasma analysis.

202

\subsection{Statistical analysis}

203 Two way ANOVA with factors of genotype (including WT, P-gp, Bcrp and P-gp/Bcrp knockout

204 mice) and time were performed on brain and plasma concentrations as well as brain/plasma

205 ratios of $\mathrm{CBD}$, risperidone and 9-hydroxy risperidone. In the instance of finding an overall main

206 effect of genotype or genotype by time interaction, Tukey’s post-hoc analysis was used to

207 individually compare WT mice to P-gp knockout, Bcrp knockout, or P-gp/Bcrp knockout mice.

208 In addition, P-gp knockout mice were compared to P-gp/Bcrp knockout mice. The latter

209 comparison is important, as compensation with transporters has been reported in knockout mice

210 studies (Tang et al., 2013; Vlaming et al., 2006). For example, double knockout of P-gp and Bcrp

211 may significantly increase the brain uptake of drugs when no altered disposition was observed in

212 single P-gp knockout or Bcrp knockout mice (Tang et al., 2013). This has been attributed to Bcrp

213 being induced in response to P-gp knockout and vice versa. Differences were deemed

214 statistically significant when $\mathrm{P}<0.05$.

\section{Results}

\subsection{P-gp or Bcrp knockout did not increase brain or plasma concentrations of CBD}




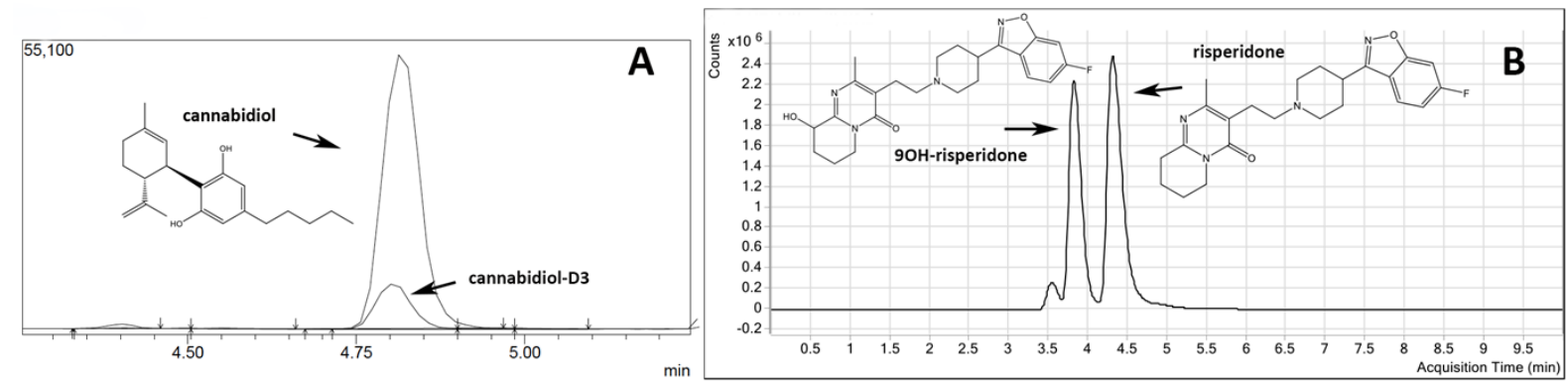

215 Figure 1. Representative chromatograms and molecular structures of tested compounds A) CBD and internal standard

216 CBD-D3 B) Risperidone and 9-OH risperidone

218 Representative chromatogram traces of CBD and the internal standard CBD-D3 are shown in

219 Figure 1A. Concentrations of CBD in brain and plasma (Fig. 2) were not altered in P-gp, Bcrp or

P-gp/Bcrp knockout mice compared to WT mice as supported by overall two-way ANOVA with

221 no main effect of genotype or a genotype by time interaction. A significant main effect of time

222 was observed in both brain $[\mathrm{F}(3,60)=30.5, \mathrm{P}<0.0001]$ and plasma $[\mathrm{F}(2,63)=34.8, \mathrm{P}<0.0001]$

223 samples, with CBD concentrations decreasing over the three hour time period in all genotypes.

224 Tukey's post-hoc comparisons confirmed that no significant differences were observed between

225 WT when individually compared to P-gp knockout, Bcrp knockout or P-gp/Bcrp knockout mice

226 at 1, 2 or $3 \mathrm{~h}$ time-points. Nor were there any significant differences between P-gp knockout and

P-gp/Bcrp knockout mice at any time-point.
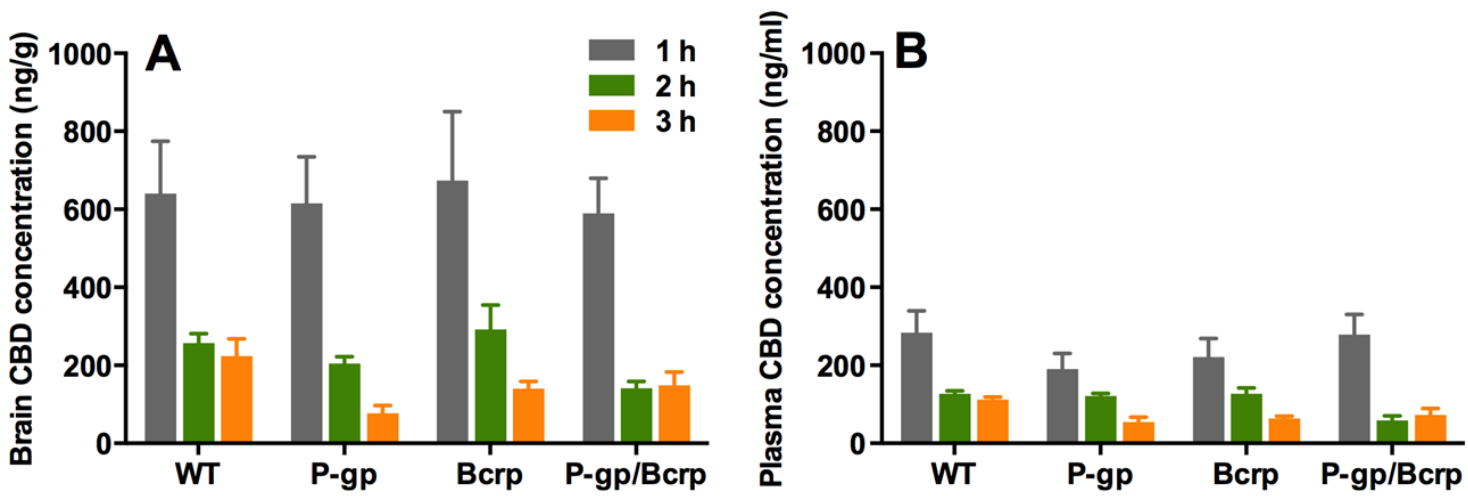

Figure 2. P-gp or Bcrp transporter knockout did not influence the CBD brain and plasma concentrations. Brain and plasma CBD samples were collected from WT and $\mathrm{ABC}$ transporter knockout mice. Samples were collected at 1, 2 and $3 \mathrm{~h}$ after an acute $10 \mathrm{mg} / \mathrm{kg}$ s.c. injection of $\mathrm{CBD}$. A) $\mathrm{CBD}$ brain concentration $\mathrm{B}$ ) $\mathrm{CBD}$ plasma concentration. $\mathrm{CBD}=$ cannabidiol, WT $=$ 
wild-type, P-gp = Abcbla/b(-) $\left(\mathrm{P}\right.$-gp knockout), Bcrp $=A b c g 2^{(--)}($Bcrp knockout $), \mathrm{P}$-gp/Bcrp $=A b c b 1 a / b^{(-/)} A b c g^{(-)}(\mathrm{P}-\mathrm{gp} / \mathrm{Bcrp}$ combined knockout). Data represent mean + S.E.M.

\subsection{P-gp or Bcrp knockout did not influence CBD brain/plasma ratios, whereas P-gp knockout profoundly increased risperidone and 9-hydroxy risperidone brain/plasma ratios}

228 No differences were observed between P-gp, Bcrp or P-gp/Bcrp knockout and WT mice (Fig.

$2293 \mathrm{~A}$ ) in their brain/plasma CBD concentration ratios (overall a ratio of approximately 2), as two-

230 way ANOVA showed no main effect of genotype and no genotype by time interaction. This was

231 confirmed by post-hoc comparisons. As CBD did not show any altered disposition in ABC

232 transporter knockout mice, we sought to show, in our hands, that other known transporter

233 substrates, that is risperidone and 9-OH risperidone, display increased brain uptake in knockout

234 animals. This would prove that our negative finding with CBD was not a false negative due to

235 some procedural error.

236 Representative chromatogram traces of risperidone and 9-OH risperidone are shown in

237 Figure 1B. Two way ANOVA indicated a significant overall main effect of genotype in the 238 risperidone and 9-hydroxy risperidone brain/plasma concentration ratios $[\mathrm{F}(3,39)=34.62, \mathrm{P}<$ $2390.0001 ; \mathrm{F}(3,39)=32.17, \mathrm{P}<0.0001$ respectively] (Fig. 3B and 3C). The brain/plasma ratio for

240 risperidone and 9-hydroxy risperidone also tended to increase over time in all genotypes [main

241 effect of time: $\mathrm{F}(1,39)=5.66, \mathrm{P}<0.05 ; \mathrm{P}(1,39)=5.65, \mathrm{P}<0.05$ respectively]. Tukey's post-hoc

242 analysis showed P-gp knockout and P-gp/Bcrp knockout had significantly greater brain/plasma

243 risperidone concentration ratios than WT mice at both $1 \mathrm{~h}$ and $3 \mathrm{~h}$ time points respectively (Ps $<$

244 0.05). In the P-gp knockout and P-gp/Bcrp knockout mice the brain/plasma risperidone ratios

245 reached as high as 13 whereas the ratio for WT mice was less than 1. Brain/plasma concentration

246 ratios of 9-hydroxy risperidone in P-gp knockout mice and P-gp/Bcrp knockout mice were

247 significantly higher than the WT mice ratio at the $3 \mathrm{~h}$ time point $(\mathrm{Ps}<0.05)$. In the P-gp 
248 knockout and P-gp/Bcrp knockout mice the brain/plasma 9-hydroxy risperidone ratio reached as

249 high as 8 whereas the ratio for WT mice was less than 1. P-gp/Bcrp knockout mice achieved a

250 significantly higher brain/plasma concentration ratio for 9-hydroxy risperidone than WT mice at

$2511 \mathrm{~h}$, however P-gp knockout mice failed to reach significance when compared to WT mice at this

252 timepoint. Although, P-gp knockout and P-gp/Bcrp knockout mice were not statistically different

253 in their brain/plasma concentration ratios for risperidone and 9-hydroxy risperidone at either the

2541 or $3 \mathrm{~h}$ timepoints implying no cooperation between P-gp and Bcrp in the transport of these

255 drugs. Bcrp knockout did not display significantly different brain/plasma concentrations of

256 risperidone and 9-hydroxy risperidone to WT at either timepoint.
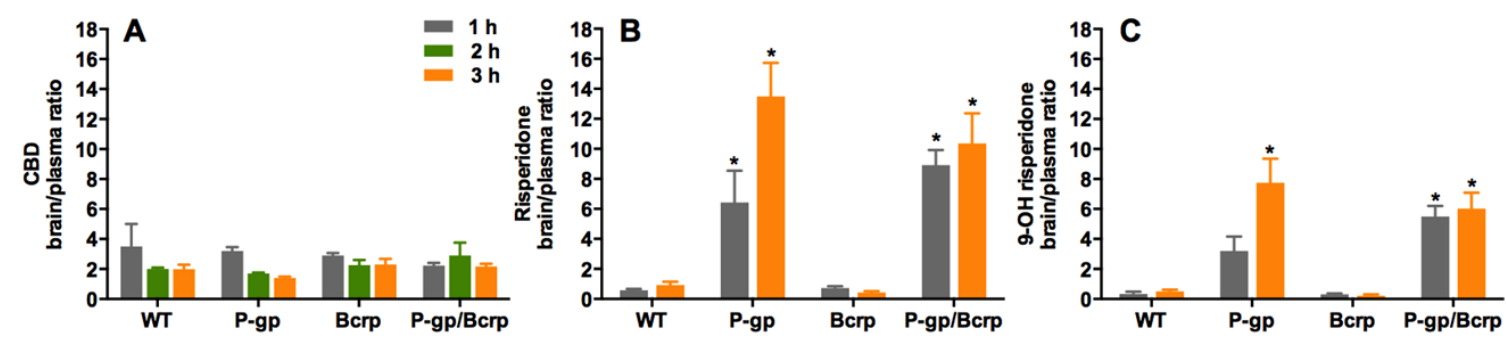

Figure 3. P-gp or Bcrp knockout did not alter CBD brain/plasma concentration ratios, whilst P-gp knockout profoundly increased risperidone and 9-hydroxy risperidone brain/plasma ratios. A) CBD brain/plasma concentration ratios $B$ ) risperidone brain/plasma concentration ratios C) 9-hydroxy risperidone brain/plasma concentration ratios. CBD = cannabidiol, 9$\mathrm{OH}$ risperidone $=$ 9-hydroxy risperidone, WT $=$ wild-type, P-gp $=A b c b l a / b^{(--)}\left(\mathrm{P}\right.$-gp knockout), Bcrp $=A b c g 2^{(--)}(\mathrm{Bcrp}$

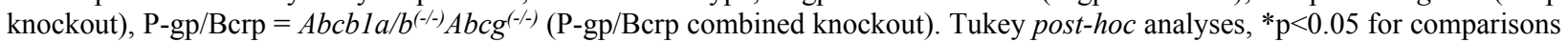
between WT and knockout mice. Data represent mean + S.E.M.

\section{Discussion}

257 This study shows that the ABC transporters P-gp and Bcrp do not influence the brain uptake of CBD, a novel antipsychotic and anticonvulsant drug. P-gp, Bcrp and P-gp/Bcrp knockout mice did not accumulate greater brain or plasma concentrations of CBD compared to WT mice, nor were the brain/plasma concentration ratios of $\mathrm{CBD}$ influenced by knockout of the $\mathrm{ABC}$

261 transporter genes. By comparison, the known substrates of P-gp risperidone and 9-hydroxy

262 risperidone (Doran et al., 2005; Ejsing, Pedersen \& Linnet, 2005; Kirschbaum et al., 2008; Wang 
263 et al., 2004), displayed increased brain/plasma concentration ratios in P-gp knockout mice

264 compared to WT mice, reaching as high as approximately 13 and 8 times respectively whereas

265 WT mice only attained ratios $<1$. Taken together these results suggest P-gp strongly regulates

266 the brain uptake of the antipsychotic drugs risperidone and 9-hydroxy risperidone but not CBD. given our prior research showing these transporters regulate the brain concentrations of $\mathrm{THC}$, the main psychoactive constituent of cannabis (Spiro et al., 2012). CBD and THC are isomers with very similar lipophilicity. However, CBD is formed when the central pyran ring of THC is opened and the oxygen in the ring is converted into a free hydroxy group (Compton et al., 1992). This subtle chemical modification yields remarkable differences in the pharmacological activity 273 of these drugs. For instance, $\mathrm{THC}$ is a partial agonist at $\mathrm{CB}_{1}$ cannabinoid receptors and therefore 274 elicits profound psychotropic effects, whilst CBD has poor affinity for the orthosteric site of this 275 receptor and doesn't have appreciable psychoactivity (Laprairie et al., 2015; Long et al., 2010). 276 CBD has a growing list of distinctive properties to THC. For example, CBD inhibits the anandamide degradative enzyme fatty acid amid hydrolase (FAAH) and activates TRPV1 278 receptors, actions not shared with THC (McPartland et al., 2015; Pertwee, 2008). Our data here provides yet another example, this time a differential substrate binding character for $\mathrm{ABC}$ 280 transporter proteins.

281 Our finding that CBD is not a substrate of murine P-gp and Bcrp is consistent with in 282 vitro data with cells expressing human transporters. CBD did not stimulate ATPase activity in 283 insect membranes expressing human P-gp and Bcrp, unlike known P-gp and Bcrp substrates 284 verapamil and sulphasalazine respectively (Holland et al., 2007; Zhu et al., 2006). Therefore it 285 appears that our results here may generalize to human transporters, although future studies 
286

287

288

289

290

291

292

293

294

295

296

297

298

299

300

301

302

303

304

305

306

307

308

assessing $\mathrm{CBD}$ transport by human $\mathrm{ABC}$ transporters using transwell assays would strengthen this viewpoint. We and others have shown that both CBD and THC inhibit P-gp and Bcrp (Feinshtein et al., 2013a; Feinshtein et al., 2013b; Holland et al., 2007; Spiro et al., 2012; Zhu et al., 2006). While THC appears to be a competitive substrate, as it is also actively transported by P-gp and Bcrp (Bonhomme-Faivre et al., 2008; Spiro et al., 2012), CBD's ability to inhibit the transporters occurs in the absence of active transport. This phenomenon is not without precedent as paracetamol and haloperidol both inhibit P-gp but are not actively transported as substrates (Feng et al., 2008; Novak et al., 2013) and gefitinib inhibits Bcrp while not being a substrate (Galetti et al., 2015).

Future studies are needed to examine whether CBD's ability to inhibit $\mathrm{ABC}$ transporters alters the pharmacokinetics of co-administered drugs that are $\mathrm{ABC}$ transporters substrates like risperidone. Interestingly co-administration of $\mathrm{CBD}$ with clobazam in children with refractory epilepsy increased plasma concentrations of clobazam and its active metabolite norclobazam by 60 and 500\% respectively (Geffrey et al., 2015). Whether norclozabam is an ABC transporter substrate is unknown, however clobazam is a duel P-gp/Bcrp substrate opening the possibility that these transporters may contribute to this drug interaction (Nakanishi et al., 2013). In addition, $\mathrm{CBD}$ inhibition of $\mathrm{ABC}$ transporters appears relevant to pharmacokinetic interactions between CBD and THC, as THC is a dual P-gp and Bcrp substrate, and CBD potentiates some of the effects of THC via increasing brain THC concentrations (Klein et al., 2011; Spiro et al., 2012; Todd \& Arnold, 2015). Extended exposure to CBD has also been shown to influence the expression of P-gp in cancer cells that is mediated by CB2 and TRPV1 receptors (Arnold et al., 2012; Holland et al., 2006). Thus future studies assessing the impact of CBD on P-gp in brain microvessels are warranted, as this may impact upon the pharmacokinetics of co-administered 
309 substrate drugs following chronic CBD exposure. Another limitation of the current study is that

310 CBD metabolites were not examined, as no commercially available analytical standards for these

311 compounds were available. One metabolite of particular interest is 7-OH CBD which appears to

312 be an active anticonvulsant with greater potency than CBD (Jiang et al., 2011; Stott et al., 2015;

313 Ujváry \& Hanuš, 2016). Future studies need to address whether CBD metabolites like 7-OH

314 CBD are ABC transporter substrates.

315 Our results suggest for the first time that risperidone and 9-hydroxy risperidone are not

316 Bcrp substrates and that there is no cooperation between P-gp and Bcrp in the transport of these

317 antipsychotic drugs. If these drugs were Bcrp substrates then the Bcrp knockout mice would

318 have displayed greater brain and plasma concentrations of these agents than WT mice. Further, if

319 these antipsychotic drugs were dual substrates of P-gp and Bcrp we would have expected the 320 double P-gp/Bcrp knockout mice to display greater brain and plasma concentrations than P-gp

321 knockout mice alone. Such observations have been made for other drugs, for example the Bcrp

322 substrates prazosin and mitoxantrone display greater brain or plasma concentrations in Bcrp

323 knockout mice than WT mice (Cisternino et al., 2004) and the dual P-gp and Bcrp substrates

324 sunitinib and dasatinib show greater brain concentrations in P-gp/Bcrp knockout mice than P-gp

325 or Bcrp knockout mice alone (Tang et al., 2013).

326 Cannabidiol is currently being assessed in randomized controlled trials as a novel 327 antipsychotic and anticonvulsant agent, supported by an array of preclinical and human data 328 (Arnold, Boucher \& Karl, 2012; Devinsky et al., 2014; Leweke et al., 2012). ABC transporters 329 may play an important role in pharmacoresistance, which is a major stumbling block in the 330 successful treatment of schizophrenia and epilepsy. Indeed the ABC transporter substrate binding 331 character is routinely assessed in the development of novel CNS therapeutics to ensure adequate 
332 brain uptake of the drug e.g. blonanserin (Inoue et al., 2012). As can be seen here, the brain

333 uptake of the commonly used antipsychotic drug risperidone and its active metabolite 9-hydroxy

334 risperidone is profoundly limited by P-gp. Similarly many anticonvulsant drugs such as

335 phenytoin, phenobarbital and clobazam are also $\mathrm{ABC}$ transporter substrates and subject to poor

336 brain uptake (Nakanishi et al., 2013; Zhang et al., 2012). Moreover, single nucleotide

337 polymorphisms (SNPs) in MDR1 increase the risk of resistance or greater interindividual

338 response to antiepileptic and antipsychotic drugs (Bozina et al., 2008; Li et al., 2014; Shaheen et

339 al., 2014; Vijayan et al., 2012). Our data support that CBD may be free from the complication of

340 reduced brain uptake or varied interindividual response to drug therapy, at least that is mediated

341 by the $\mathrm{ABC}$ transporters $\mathrm{P}$-gp and Bcrp. These findings provide evidence for the favourable

342 pharmacokinetic properties of CBD in the treatment of CNS disorders and help build the case for

343 the development of CBD as a therapeutic agent.

\section{References}

345

346

347

348

349

350

351

352

353

354

355

356

357

358

359
Arnold JC, Boucher AA, and Karl T. 2012. The Yin and Yang of Cannabis-induced Psychosis: the Actions of Delta(9)-Tetrahydrocannabinol and Cannabidiol in Rodent Models of Schizophrenia. Current Pharmaceutical Design 18:5113-5130.

Arnold JC, Hone P, Holland ML, and Allen JD. 2012. CB 2 and TRPV 1 receptors mediate cannabinoid actions on MDR1 expression in multidrug resistant cells. Pharmacological Reports 64:751-757.

Aronica E, Gorter JA, Redeker S, Van Vliet EA, Ramkema M, Scheffer GL, Scheper RJ, Van Der Valk P, Leenstra S, and Baayen JC. 2005. Localization of breast cancer resistance protein (BCRP) in microvessel endothelium of human control and epileptic brain. Epilepsia 46:849-857.

Bauer M, Karch R, Zeitlinger M, Liu J, Koepp MJ, Asselin MC, Sisodiya SM, Hainfellner JA, Wadsak W, Mitterhauser M, Muller M, Pataraia E, and Langer O. 2014. In vivo Pglycoprotein function before and after epilepsy surgery. Neurology 83:1326-1331.

Bebawy M, and Chetty M. 2008. Differential pharmacological regulation of drug efflux and pharmacoresistant schizophrenia. Bioessays 30:183-188. 
360 Bonhomme-Faivre L, Benyamina A, Reynaud M, Farinotti R, and Abbara C. 2008. Disposition

361

362

363

364

365

366

367

368

369

370

371

372

373

374

375

376

377

378

379

380

381

382

383

384

385

386

387

388

389

390

391

392

393

394

395

396

397

398

399

400

401

402

403

404

405 of Delta tetrahydrocannabinol in CF1 mice deficient in mdrla P-glycoprotein. Addiction Biology 13:295-300.

Boulton DW, DeVane CL, Liston HL, and Markowitz JS. 2002. In vitro P-glycoprotein affinity for atypical and conventional antipsychotics. Life Sciences 71:163-169.

Bozina N, Kuzman MR, Medved V, Jovanovic N, Sertic J, and Hotujac L. 2008. Associations between MDR1 gene polymorphisms and schizophrenia and therapeutic response to olanzapine in female schizophrenic patients. Journal of Psychiatric Research 42:89-97.

Brandt C, Bethmann K, Gastens AM, and Löscher W. 2006. The multidrug transporter hypothesis of drug resistance in epilepsy: proof-of-principle in a rat model of temporal lobe epilepsy. Neurobiology of Disease 24:202-211.

Bumb JM, Enning F, and Leweke FM. 2015. Drug repurposing and emerging adjunctive treatments for schizophrenia. Expert Opinion on Pharmacotherapy 16:1049-1067.

Cisternino S, Mercier C, Bourasset F, Roux F, and Scherrmann J-M. 2004. Expression, upregulation, and transport activity of the multidrug-resistance protein Abcg2 at the mouse blood-brain barrier. Cancer Research 64:3296-3301.

Compton DR, Johnson MR, Melvin LS, and Martin BR. 1992. Pharmacological profile of a series of bicyclic cannabinoid analogs: classification as cannabimimetic agents. The Journal of Pharmacology and Experimental Therapeutics 260:201-209.

de Klerk OL, Willemsen AT, Bosker FJ, Bartels AL, Hendrikse NH, den Boer JA, and Dierckx RA. 2010. Regional increase in P-glycoprotein function in the blood-brain barrier of patients with chronic schizophrenia:: A PET study with [11C] verapamil as a probe for Pglycoprotein function. Psychiatry Research: Neuroimaging 183:151-156.

Devinsky O, Cilio MR, Cross H, Fernandez-Ruiz J, French J, Hill C, Katz R, Di Marzo V, Jutras-Aswad D, Notcutt WG, Martinez-Orgado J, Robson PJ, Rohrback BG, Thiele E, Whalley B, and Friedman D. 2014. Cannabidiol: pharmacology and potential therapeutic role in epilepsy and other neuropsychiatric disorders. Epilepsia 55:791-802.

Doran A, Obach RS, Smith BJ, Hosea NA, Becker S, Callegari E, Chen C, Chen X, Choo E, and Cianfrogna J. 2005. The impact of P-glycoprotein on the disposition of drugs targeted for indications of the central nervous system: evaluation using the MDR1A/1B knockout mouse model. Drug Metabolism and Disposition 33:165-174.

Ejsing TB, Pedersen AD, and Linnet K. 2005. P-glycoprotein interaction with risperidone and 9$\mathrm{OH}$-risperidone studied in vitro, in knock-out mice and in drug-drug interaction experiments. Human Psychopharmacology 20:493-500.

Feinshtein V, Erez O, Ben-Zvi Z, Erez N, Eshkoli T, Sheizaf B, Sheiner E, Huleihel M, and Holcberg G. 2013a. Cannabidiol changes P-gp and BCRP expression in trophoblast cell lines. PeerJ 1:e153. 10.7717/peerj.153

Feinshtein V, Erez O, Ben-Zvi Z, Eshkoli T, Sheizaf B, Sheiner E, and Holcberg G. 2013 b. Cannabidiol enhances xenobiotic permeability through the human placental barrier by direct inhibition of breast cancer resistance protein: an ex vivo study. American Journal of Obstetrics and Gynecology 209:573.e1-573.e15.

Feng B, Mills JB, Davidson RE, Mireles RJ, Janiszewski JS, Troutman MD, and de Morais SM. 2008. In vitro P-glycoprotein assays to predict the in vivo interactions of P-glycoprotein with drugs in the central nervous system. Drug Metabolism and Disposition 36:268-275.

French JA. 2013. P-glycoprotein expression and antiepileptic drug resistance. The Lancet Neurology 12:732-733. 
406

407

408

409

410

411

412

413

414

415

416

417

418

419

420

421

422

423

424

425

426

427

428

429

430

431

432

433

434

435

436

437

438

439

440

441

442

443

444

445

446

447

448

449

450

451

Galetti M, Petronini PG, Fumarola C, Cretella D, La Monica S, Bonelli M, Cavazzoni A, Saccani F, Caffarra C, and Andreoli R. 2015. Effect of ABCG2/BCRP Expression on Efflux and Uptake of Gefitinib in NSCLC Cell Lines. PLoS One 10:e141795.

Geffrey AL, Pollack SF, Bruno PL, and Thiele EA. 2015. Drug-drug interaction between clobazam and cannabidiol in children with refractory epilepsy. Epilepsia 56:1246 1251.

Hee Choi Y, and Yu A-M. 2014. ABC transporters in multidrug resistance and pharmacokinetics, and strategies for drug development. Current Pharmaceutical Design 20:793-807.

Holland ML, Lau DT, Allen JD, and Arnold JC. 2007. The multidrug transporter ABCG2 (BCRP) is inhibited by plant-derived cannabinoids. British Journal of Pharmacology 152:815-824.

Holland ML, Panetta JA, Hoskins JM, Bebawy M, Roufogalis BD, Allen JD, and Arnold JC. 2006. The effects of cannabinoids on P-glycoprotein transport and expression in multidrug resistant cells. Biochemical Pharmacology 71:1146-1154.

Hoosain FG, Choonara YE, Tomar LK, Kumar P, Tyagi C, du Toit LC, and Pillay V. 2015. Bypassing P-glycoprotein drug efflux mechanisms: possible applications in pharmacoresistant schizophrenia therapy. Biomed Research International 2015:21.

Inoue T, Katsumata T, Yabuki M, Yamaguchi N, Osada K, Tagawa M, Ogawa Y, Haga T, Sogame Y, Hashizume T, Watanabe T, and Taguchi A. 2012. Blonanserin, a novel atypical antipsychotic agent not actively transported as substrate by P-glycoprotein. Progress in Neuropsychopharmacology \& Biological Psychiatry 39:156-162.

Iseger TA, and Bossong MG. 2015. A systematic review of the antipsychotic properties of cannabidiol in humans. Schizophrenia Research 162:153-161.

Jiang R, Yamaori S, Takeda S, Yamamoto I, and Watanabe K. 2011. Identification of cytochrome P450 enzymes responsible for metabolism of cannabidiol by human liver microsomes. Life Sciences 89:165-170.

Johnston J, Lintzeris N, Allsop DJ, Suraev A, Booth J, Carson DS, Helliwell D, Winstock A, and McGregor IS. 2014. Lithium carbonate in the management of cannabis withdrawal: a randomized placebo-controlled trial in an inpatient setting. Psychopharmacology 231:4623-4636.

Jones NA, Glyn SE, Akiyama S, Hill TD, Hill AJ, Weston SE, Burnett MD, Yamasaki Y, Stephens GJ, and Whalley BJ. 2012. Cannabidiol exerts anti-convulsant effects in animal models of temporal lobe and partial seizures. Seizure 21:344-352.

Jones NA, Hill AJ, Smith I, Bevan SA, Williams CM, Whalley BJ, and Stephens GJ. 2010. Cannabidiol displays antiepileptiform and antiseizure properties in vitro and in vivo. The Journal of Pharmacology and Experimental Therapeutics 332:569-577.

Jonker JW, Buitelaar M, Wagenaar E, van der Valk MA, Scheffer GL, Scheper RJ, Plösch T, Kuipers F, Elferink RPO, and Rosing H. 2002. The breast cancer resistance protein protects against a major chlorophyll-derived dietary phototoxin and protoporphyria. Proceedings of the National Academy of Sciences 99:15649-15654.

Kathawala RJ, Gupta P, Ashby CR, and Chen Z-S. 2015. The modulation of ABC transportermediated multidrug resistance in cancer: A review of the past decade. Drug Resistance Updates 18:1-17.

Kirschbaum KM, Henken S, Hiemke C, and Schmitt U. 2008. Pharmacodynamic consequences of P-glycoprotein-dependent pharmacokinetics of risperidone and haloperidol in mice. Behavioural Brain Research 188:298-303. 
452 Klein C, Karanges E, Spiro A, Wong A, Spencer J, Huynh T, Gunasekaran N, Karl T, Long LE,

453

454

455

456

457

458

459

460

461

462

463

464

465

466

467

468

469

470

471

472

473

474

475

476

477

478

479

480

481

482

483

484

485

486

487

488

489

490

491

492

493

494

495
Huang XF, Liu K, Arnold JC, and McGregor IS. 2011. Cannabidiol potentiates Delta(9)tetrahydrocannabinol (THC) behavioural effects and alters THC pharmacokinetics during acute and chronic treatment in adolescent rats. Psychopharmacology 218:443-457.

Laprairie R, Bagher A, Kelly M, and Denovan-Wright E. 2015. Cannabidiol is a negative allosteric modulator of the cannabinoid CB1 receptor. British Journal of Pharmacology 172:4790-4805.

Lazarowski A, Czornyj L, Lubienieki F, Girardi E, Vazquez S, and D'Giano C. 2007. ABC transporters during epilepsy and mechanisms underlying multidrug resistance in refractory epilepsy. Epilepsia 48:140-149.

Leweke FM, Piomelli D, Pahlisch F, Muhl D, Gerth CW, Hoyer C, Klosterkotter J, Hellmich M, and Koethe D. 2012. Cannabidiol enhances anandamide signaling and alleviates psychotic symptoms of schizophrenia. Transcultural Psychiatry 2:e94.

Li M, Tan J, Yang X, Su L, Xie J, Liang B, Long J, Jiang H, Wei Q, Shen T, Chen Q, Yan Y, $\mathrm{Wu} \mathrm{G}$, and Gu L. 2014. The ABCB1-C3435T polymorphism likely acts as a risk factor for resistance to antiepileptic drugs. Epilepsy Research 108:1052-1067.

Long LE, Chesworth R, Huang X-F, McGregor IS, Arnold JC, and Karl T. 2010. A behavioural comparison of acute and chronic $\Delta 9$-tetrahydrocannabinol and cannabidiol in C57BL/6JArc mice. International Journal of Neuropsychopharmacology 13:861-876.

Long LE, Chesworth R, Huang X-F, McGregor IS, Arnold JC, and Karl T. 2013. Transmembrane domain Nrg1 mutant mice show altered susceptibility to the neurobehavioural actions of repeated THC exposure in adolescence. International Journal of Neuropsychopharmacology 16:163-113.

Longo DL, Friedman D, and Devinsky O. 2015. Cannabinoids in the Treatment of Epilepsy. New England Journal of Medicine 373:1048-1058.

Löscher W, and Potschka H. 2005. Blood-brain barrier active efflux transporters: ATP-binding cassette gene family. NeuroRx 2:86-98.

Luna-Tortós C, Fedrowitz M, and Löscher W. 2008. Several major antiepileptic drugs are substrates for human P-glycoprotein. Neuropsychopharmacology 55:1364-1375.

Mao K, You C, Lei D, and Zhang H. 2015. High dosage of cannabidiol (CBD) alleviates pentylenetetrazole-induced epilepsy in rats by exerting an anticonvulsive effect. International Journal of Clinical and Experimental Medicine 8:8820-8827.

McPartland JM, Duncan M, Di Marzo V, and Pertwee RG. 2015. Are cannabidiol and $\Delta 9$-tetrahydrocannabivarin negative modulators of the endocannabinoid system? A systematic review. British Journal of Pharmacology 172:737-753.

Nakanishi H, Yonezawa A, Matsubara K, and Yano I. 2013. Impact of P-glycoprotein and breast cancer resistance protein on the brain distribution of antiepileptic drugs in knockout mouse models. European Journal of Pharmacology 710:20-28.

Novak A, Carpini GD, Ruiz ML, Luquita MG, Rubio MC, Mottino AD, and Ghanem CI. 2013. Acetaminophen inhibits intestinal p-glycoprotein transport activity. Journal of Pharmacological Sciences 102:3830-3837.

Pacchioni AM, Gabriele A, Donovan JL, DeVane CL, and See RE. 2010. P-glycoprotein inhibition potentiates the behavioural and neurochemical actions of risperidone in rats. International Journal of Neuropsychopharmacology 13:1067-1077. 
496

497

498

499

500

501

502

503

504

505

506

507

508

509

510

511

512

513

514

515

516

517

518

519

520

521

522

523

524

525

526

527

528

529

530

531

532

533

534

535

536

537

538

539

540

541

Pertwee R. 2008. The diverse CB1 and CB2 receptor pharmacology of three plant cannabinoids: $\Delta$ 9-tetrahydrocannabinol, cannabidiol and $\Delta 9$-tetrahydrocannabivarin. British Journal of Pharmacology 153:199-215.

Römermann K, Helmer R, and Löscher W. 2015. The antiepileptic drug lamotrigine is a substrate of mouse and human breast cancer resistance protein (ABCG2). Neuropharmacology 93:7-14.

Rosenberg EC, Tsien RW, Whalley BJ, and Devinsky O. 2015. Cannabinoids and Epilepsy. Neurotherapeutics 12:747-768.

Schinkel A, Mol C, Wagenaar E, Van Deemter L, Smit J, and Borst P. 1995. Multidrug resistance and the role of P-glycoprotein knockout mice. European Journal of Cancer 31:1295-1298.

Schinkel AH, Mayer U, Wagenaar E, Mol CA, Van Deemter L, Smit JJ, Van Der Valk MA, Voordouw AC, Spits H, and Van Tellingen O. 1997. Normal viability and altered pharmacokinetics in mice lacking mdr1-type (drug-transporting) P-glycoproteins. Proceedings of the National Academy of Sciences 94:4028-4033.

Shaheen U, Prasad DK, Sharma V, Suryaprabha T, Ahuja YR, Jyothy A, and Munshi A. 2014. Significance of MDR1 gene polymorphism C3435T in predicting drug response in epilepsy. Epilepsy Research 108:251-256.

Spiro AS, Wong A, Boucher AA, and Arnold JC. 2012. Enhanced brain disposition and effects of Delta9-tetrahydrocannabinol in P-glycoprotein and breast cancer resistance protein knockout mice. PLoS One 7:e35937.

Stott C, Jones N, Whalley B, Stephens G, and Williams C. 2015. 7-oh-cannabidiol (7-oh-cbd) and/or 7-oh-cannabidivarin (7-oh-cbdv) for use in the treatment of epilepsy. Google Patents.

Tang SC, de Vries N, Sparidans RW, Wagenaar E, Beijnen JH, and Schinkel AH. 2013. Impact of P-glycoprotein (ABCB1) and breast cancer resistance protein (ABCG2) gene dosage on plasma pharmacokinetics and brain accumulation of dasatinib, sorafenib, and sunitinib. Journal of Pharmacology and Experimental Therapeutics 346:486-494.

Todd SM, and Arnold JC. 2016. Neural correlates of cannabidiol and Delta9tetrahydrocannabinol interactions in mice: implications for medical cannabis. British Journal of Pharmacology 173:53-65.

Ujváry I, and Hanuš L. 2016. Human Metabolites of Cannabidiol: A Review on Their Formation, Biological Activity, and Relevance in Therapy. Cannabis and Cannabinoid Research 1:90-101.

van Os J, and Kapur S. 2009. Schizophrenia. Lancet 374:635-645.

Van Vliet EA, Redeker S, Aronica E, Edelbroek PM, and Gorter JA. 2005. Expression of multidrug transporters MRP1, MRP2, and BCRP shortly after status epilepticus, during the latent period, and in chronic epileptic rats. Epilepsia 46:1569-1580.

Vijayan NN, Mathew A, Balan S, Natarajan C, Nair CM, Allencherry PM, and Banerjee M. 2012. Antipsychotic drug dosage and therapeutic response in schizophrenia is influenced by ABCB1 genotypes: a study from a south Indian perspective. Pharmacogenomics 13:1119-1127.

Vlaming M, Mohrmann K, Wagenaar E, de Waart DR, Elferink RO, Lagas JS, van Tellingen O, Vainchtein LD, Rosing H, and Beijnen JH. 2006. Carcinogen and anticancer drug transport by Mrp2 in vivo: studies using Mrp2 (Abcc2) knockout mice. Journal of Pharmacology and Experimental Therapeutics 318:319-327. 
542 Wang JS, Ruan Y, Taylor RM, Donovan JL, Markowitz JS, and DeVane CL. 2004. The brain

543

544

545

546

547

548

549

550

551

552

553

554

555

556 entry of risperidone and 9-hydroxyrisperidone is greatly limited by P-glycoprotein. International Journal of Neuropsychopharmacology 7:415-419.

Wolking S, Schaeffeler E, Lerche H, Schwab M, and Nies AT. 2015. Impact of Genetic Polymorphisms of ABCB1 (MDR1, P-Glycoprotein) on Drug Disposition and Potential Clinical Implications: Update of the Literature. Clinical Pharmacokinetics 54:709-735.

Zhang C, Kwan P, Zuo Z, and Baum L. 2010. In vitro concentration dependent transport of phenytoin and phenobarbital, but not ethosuximide, by human P-glycoprotein. Life Sciences 86:899-905.

Zhang C, Kwan P, Zuo Z, and Baum L. 2012. The transport of antiepileptic drugs by Pglycoprotein. Advanced Drug Delivery Reviews 64:930-942.

Zhu HJ, Wang JS, Markowitz JS, Donovan JL, Gibson BB, Gefroh HA, and Devane CL. 2006. Characterization of P-glycoprotein inhibition by major cannabinoids from marijuana. Journal of Pharmacology and Experimental Ttherapeutics 317:850-857. 